\title{
The Short Interpersonal Reactions Inventory, Self-regulation and Differentiation scales in an older Australian twin sample
}

\author{
Katherine M. Kirk*, Nicholas G. Martin \\ Epidemiology Unit, Queensland Institute of Medical Research, Post Office, Royal Brisbane Hospital, Brisbane, QLD 4029, \\ Australia
}

Received 8 October 1997

\begin{abstract}
An English translation of the Differentiation and Self-regulation extension scales has been used in conjunction with a reduced form of the Short Interpersonal Reactions Inventory (SIRI) in a sample of 2844 Australian twins aged over 50. Significant correlation was found between Type 1 (cancer-prone) and Type 2 (coronary heart disease prone), and between Self-regulation and Type 4 (healthy). The low correlations reported in other studies between the two alternative subscales of Type 4 are also observed. The Differentiation scales of Agitation and Inhibition were not found to significantly improve discrimination between Grossarth-Maticek's personality Type 1 and 2 subjects in this study. (C) 1998 Elsevier Science Ltd. All rights reserved.
\end{abstract}

Key words: SIRI; Self-regulation; Differentiation; Inhibition; Agitation

\section{Introduction}

For many years there has been considerable interest in the relationship between personality and health. Friedman and Rosenman (1974) identified two opposing behavior patterns - "Type A", characterised by aggression, tension and hostility, and a healthier alternative behavior pattern "Type B" - and suggested that Type A behavior was a significant cause of coronary heart disease. Extending this concept, a "Type C" behavior predictive of the development of cancer was proposed by Greer and Watson (1985), with principal features of emotional response suppression, conformity/compliance, unassertiveness and patience. Grossarth-Maticek and Eysenck (1990) proposed the existence of six behavior or personality types, with Type 1 a cancer-prone personality

\footnotetext{
*Corresponding author. Fax: +61-7-3362-0101; E-mail: kathe(a qimr.edu.au.
} 
type with characteristics similar to Greer and Watson's "Type C". Type 2, on the other hand, is coronary heart disease-prone, with a reaction to stress of chronic irritation and anger (Temoshok, 1987). Type 3 is characterised by ambivalence and the tendency to alternate between the typical reactions of Types 1 and 2, and Type 4 is the "healthy" group in the typology, displaying autonomous behavior. Both these latter types are considered to be not prone to either coronary heart disease or cancer. The rational/anti-emotional Type 5 was proposed to be related to depression and cancer, while Type 6 demonstrates anti-social, egocentric and possibly criminal tendencies, with a proneness to drug addiction.

Two questionnaire measures with similar psychometric properties were devised to discriminate between the six different personality types (Grossarth-Maticek and Eysenck, 1990). The first of these was the 182-item Personality Stress Questionnaire (PSQ), while the other was the 70-item Short Interpersonal Reactions Inventory (SIRI). In each case, a number of items with yes/no responses relating to each of the personality types was used. The scale for Type 4 included both positively and negatively scored items. Grossarth-Maticek and Eysenck recommended the use of the SIRI in preference to the PSQ for English-speaking samples, as the former was translated idiomatically from the original German, while the "most correct" translation was used for the latter.

Amclang and Schmidt-Rathjens (1992) conducted a study combining the PSQ and SIRI instruments with similar items from other related measurement instruments, giving a final set of 275 items. They found no internal differentiation of the combined constructs corresponding to Types 1 and 2, and suggested that they formed a common dimension at one end of a bipolar factor, with health/autonomy (corresponding to Type 4) at the opposite pole. Larsson et al. (1995) and Roberts et al. (1995) also experienced difficulty in allocating subjects to single personality types using the SIRI, and noted that theoretical refinement of the personality types was needed, particularly with regard to low correlation between the positive and negative subscales of Type 4 . Roberts et al. also found that Types 3 and 6 (alternating reaction and antisocial/egocentric) could reasonably be considered as a single scale.

In response to the difficulties encountered in distinguishing between Types 1 and 2 in noninterview derived responses, Grossarth-Maticek and colleagues developed extension scales of Selfregulation and Differentiation. The Differentiation scale, as the name suggests, was designed to aid the discrimination process. It consists of two subscales, Inhibition and Agitation, which were hypothesised by Grossarth-Maticek to be predictors for Types 1 and 2, respectively. A study of 40-60 year old German subjects (Pfundt, 1994) using the SIRI with the Sclf-regulation and Differentiation scales reported that Type 4 and self-regulation were closely related, and that the Agitation subscale in particular is useful in discriminating between Types 1 and 2 .

In a preliminary study involving a sample of Australian twins, Roberts et al. (1995) found that the reliability of the SIRI was increased when the Type scales were shortened to include only the five highest-scoring items identified through factor analysis. The objective of the current study is to evaluate the properties of this reduced form of the SIRI and an English translation of the Selfregulation and Differentiation extension scales in a large sample of older Australian twins.

\section{Method}

A study designed to cover a wide range of health issues affecting older people was undertaken as a multi-wave mailout between 1993 and 1995. 2281 pairs of twins aged over 50 and listed with 
the Australian Twin Registry were invited to participate, by completion of a 16-page questionnaire. Included in the questionnaire were a range of psychological scales, lifestyle measures assessing smoking, alcohol consumption and physical activity, and a detailed disease checklist requesting information on occurrence and age of onset for the respondent and their co-twin. Questionnaire responses were received from 3116 individuals (1279 complete pairs and 558 singles), with a response rate for individuals (excluding deaths and non-contacts) of $71 \%$, and a complete pairs response rate of $61 \%$. The group of respondents consisted of 2197 females (response rate $75 \%$ ) and 919 males $(63 \%)$. The mean age of respondents was $61.5 \pm 8.7$ years, with an age range for males of 50 to 89 years, and for females of 50 to 94 years. Subjects with more than $10 \%$ of responses missing from the total of 70 items in the combined scales have been excluded from the analysis, resulting in a final sample of 2844 individuals ( 1985 females and 859 males).

Among the psychological measures used in the study were a reduced version of the SIRI, along with the Self-regulation scale and both the Agitation and Inhibition sections of the Differentiation scale. Since the primary aim of the study was to consider health issues affecting older people, items from Types 3 and 6 (which have not been associated with proneness to any disease) were omitted. The Type 1, 2 and 4 scales were also reduced in length in line with the factor analysis of Roberts et al. (1995), with 5 items being retained for each of Types 1, 2, 4(a) (Type 4 positively scored items) and 4(b) (Type 4 negatively scored items). Since previous studies have varied in their treatment of Type 4, it was analysed here as a complete construct, and also separated into its constituent parts (positively and negatively scored items). The direction of scoring for Type 4(b) items was reversed prior to analysis, in order to maintain consistency. The full 10 -item scale for Type 5 was also included.

The Self-regulation and Differentiation scales had not been previously used with an Englishspeaking sample. Translation resulted in lengthy and convoluted items, which were refined to make them more appropriate and interpretable to the target population. Preservation of the meaning of the original items was accomplished using an iterative back-translation process involving native speakers of English and German. To minimise repetition and reduce length, eight items with almost exact (but reversed) wording were deleted from the Differentiation Scale, resulting in a 9item Inhibition scale and an 8-item Agitation scale. The English versions of the Self-regulation and Differentiation Scales as used by us, along with the reduced form of the SIRI, appear in Appendix 1. A three-point response set ("agree", "not sure", "disagree") was used for all items. This was considered preferable in a mailed questionnaire to the two-point response set used by Fysenck (1991), as people are less likely to be deterred from answering difficult questions. To avoid response set bias, the items shown in Appendix 1 were randomised inter se. In addition, the items on Type 5 (rationalism/anti-emotionalism) were interspersed with instruments addressing optimism/pessimism and health locus of control.

Data analysis was performed using PROC FACTOR, PROC FREQ and PROC CORR from SAS 6.11 (SAS Institute, 1995).

\section{Results}

\subsection{Survey responses}

The percentage of male and female respondents agreeing with each questionnaire item is shown in Appendix 1. Inspection of these results reveals considerable differences between males and 
Table 1

Comparison of SIRI type, Self-regulation and Differentiation scores for males and females

\begin{tabular}{|c|c|c|c|c|c|}
\hline & \multicolumn{2}{|c|}{ Females $(n=1985)$} & \multicolumn{2}{|c|}{ Males $(n=859)$} & \multirow[b]{2}{*}{$P$-value } \\
\hline & Mean & $\mathrm{SD}$ & Mean & SD & \\
\hline Type 1 & 4.54 & 2.98 & 3.28 & 2.69 & 0.0001 \\
\hline Type 2 & 2.48 & 2.50 & 1.76 & 2.20 & 0.0001 \\
\hline Type 4 & 15.04 & 3.32 & 15.65 & 3.18 & 0.0001 \\
\hline Type $4 a$ & 7.27 & 2.13 & 7.53 & 2.04 & 0.0603 \\
\hline Type 4b & 7.76 & 2.30 & 8.12 & 2.14 & 0.0051 \\
\hline Type 5 & 11.32 & 3.40 & 12.22 & 3.38 & 0.0001 \\
\hline Self-regulation & 33.59 & 6.09 & 34.18 & 6.17 & 0.1188 \\
\hline Agitation & 6.44 & 1.70 & 6.40 & 1.73 & 0.5228 \\
\hline Inhibition & 11.20 & 3.50 & 11.09 & 3.68 & 0.7110 \\
\hline
\end{tabular}

Significance of sex difference is shown (2-tail Kolmogorov-Smirnov test).

females in their response to individual items. Following the procedure of Roberts et al. (1995), scale scores were calculated for each subject, based on their responses to each item in the SIRI Types and Self-regulation and Differentiation scales. Using the Kolmogorov-Smirnov test (DeGroot, 1986), the distribution of scores for each scale were compared for male and female subjects. Mean and standard deviation values for females and males, along with the KolmogorovSmirnov test results, appear in Table 1 for each scale. Significant differences in distribution $(P<0.001)$ were found for SIRI Type 1, Type 2, Type 4 and Type 5, but not for the Self-regulation or Differentiation scales, or the two individual subscales of Type 4. Scales found to correlate with age $(P<0.001)$ were Type $5(r=0.24$ for females, 0.18 for males), Self-regulation $(r=0.17$ for females, 0.22 for males) and Inhibition (females only, $r=0.13$ ).

\subsection{Inter-scale correlations}

Polychoric correlations between the reduced SIRI Types and the Self-regulation and Differentiation scales are shown in Table 2. Since the response distributions of several scales differed markedly between male and female subjects, the polychoric correlations were calculated separately for each group, with results for females appearing at upper right, and results for males at lower left. However, inspection of the two halves of Table 2 reveal a high degree of congruence between the interscale correlations. This result demonstrates that although the scale response distributions differ, the relationship between the scales is the same for male and female subjects.

Type 1 is highly correlated with Type 2, and both demonstrate a strong negative correlation with Type 4(b), but not Type 4(a). Significant correlation was observed between Type 1 and both of the Differentiation subscales, whereas Type 2 only correlated significantly with Agitation. Type 4 correlated highly with the Self-regulation scale, and negatively with Agitation. No significant correlation was observed with the Inhibition scale. However, the breakdown into Types 4(a) and 
Table 2

Polychoric correlation matrix of SIRI types, Self-regulation, Agitation and Inhibition scales for females and males

\begin{tabular}{|c|c|c|c|c|c|c|c|c|c|}
\hline & \multicolumn{9}{|c|}{ Females $(n=1985)$} \\
\hline & Type 1 & Type 2 & Type 4 & Type 4a & Type 4b & Type 5 & SR & Agitation & Inhibition \\
\hline Type 1 & 1 & 0.44 & -0.37 & -0.12 & -0.45 & 0.21 & -0.18 & 0.33 & 0.32 \\
\hline Type 2 & 0.40 & 1 & -0.50 & -0.11 & -0.64 & 0.20 & -0.21 & 0.52 & 0.11 \\
\hline Type 4 & -0.30 & -0.53 & 1 & 0.76 & 0.80 & $-0.08^{*}$ & 0.46 & -0.46 & $0.02^{*}$ \\
\hline Type $4 a$ & $-0.08^{*}$ & -0.16 & 0.80 & 1 & 0.13 & 0.09 & 0.45 & -0.13 & 0.10 \\
\hline Type $4 b$ & -0.40 & -0.66 & 0.80 & 0.17 & 1 & -0.20 & 0.26 & -0.56 & $-0.07^{*}$ \\
\hline Type 5 & 0.17 & 0.19 & $-0.01^{*}$ & 0.15 & -0.15 & 1 & 0.23 & 0.10 & 0.39 \\
\hline SR & $-0.01^{*}$ & -0.17 & 0.46 & 0.47 & 0.25 & 0.27 & 1 & -0.20 & 0.22 \\
\hline Agitation & 0.25 & 0.55 & -0.47 & -0.17 & -0.55 & $0.08^{*}$ & -0.20 & 1 & $-0.09^{*}$ \\
\hline Inhibition & 0.32 & $0.06^{*}$ & $0.07^{*}$ & 0.16 & $0.06^{*}$ & 0.28 & 0.24 & -0.17 & 1 \\
\hline
\end{tabular}

Males $(n=859)$.

$\mathrm{SR}$-self-regulation.

${ }^{*} r$ not significant for $P<0.001$.

4(b) demonstrates that it is the Type 4(a) items that correlate highly with the Self-regulation items, and the Type 4(b) items which correlate highly with the Agitation items.

The effectiveness of the Differentiation scales depends on their ability to discriminate between Type 1 and Type 2 subjects. If the discrimination is improved, then subjects obtaining higher scores on the Differentiation scales should demonstrate a lower correlation between Type 1 and 2 individuals. Table 3 outlines the results obtained from dividing each of the Differentiation scale scores and the Self-regulation scale scores into quartiles, and comparing the Type 1-Type 2 intercorrelations. For each of the Agitation and Inhibition scales, there is an overall trend towards the expected decrease in intercorrelation, although the results are not statistically significant. By contrast, the intercorrelation between Types 1 and 2 appears to increase with the Self-regulation score. Again, this result is not statistically significant.

Table 3

Intercorrelation between SIRI types 1 and 2 stratified by scores on Agitation, Inhibition and Self-regulation scales

\begin{tabular}{|c|c|c|c|c|c|c|}
\hline \multirow[t]{2}{*}{ Quartile } & \multicolumn{2}{|c|}{ Agitation $(r \pm \mathrm{ASE})$} & \multicolumn{2}{|c|}{ Inhibition ( $r \pm \mathrm{ASE})$} & \multicolumn{2}{|c|}{ Self-regulation ( $r \pm \mathrm{ASE})$} \\
\hline & $\mathrm{F}(n=1985)$ & $\mathrm{M}(n=859)$ & $\mathrm{F}(n=1985)$ & $\mathrm{M}(n=859)$ & $\mathrm{F}(n=1985)$ & $\mathrm{M}(n=859)$ \\
\hline 1 (low) & $0.37 \pm 0.03$ & $0.43 \pm 0.05$ & $0.46 \pm 0.04$ & $0.38 \pm 0.07$ & $0.39 \pm 0.04$ & $0.34 \pm 0.07$ \\
\hline 2 & $0.40 \pm 0.05$ & $0.25 \pm 0.10$ & $0.45 \pm 0.04$ & $0.43 \pm 0.05$ & $0.37 \pm 0.04$ & $0.34 \pm 0.06$ \\
\hline 3 & $0.36 \pm 0.05$ & $0.28 \pm 0.09$ & $0.43 \pm 0.04$ & $0.35 \pm 0.07$ & $0.45 \pm 0.04$ & $0.46 \pm 0.06$ \\
\hline 4 (high) & $0.31 \pm 0.04$ & $0.28 \pm 0.07$ & $0.36 \pm 0.05$ & $0.38 \pm 0.08$ & $0.49 \pm 0.04$ & $0.54 \pm 0.06$ \\
\hline
\end{tabular}


Table 4

Cronbach $\alpha$ for possible factor solutions for females and males

\begin{tabular}{|c|c|c|c|c|c|c|}
\hline & \multicolumn{3}{|c|}{ Females $(n=1985)$} & \multicolumn{3}{|c|}{ Males $(n=859)$} \\
\hline & 5 factors & 4 factors & 3 factors & 5 factors & 4 factors & 3 factors \\
\hline$\alpha_{1}$ & 0.90 & 0.89 & 0.87 & 0.90 & 0.87 & 0.83 \\
\hline$\alpha_{2}$ & 0.82 & 0.83 & 0.86 & 0.81 & 0.88 & 0.88 \\
\hline$\alpha_{3}$ & 0.82 & 0.86 & 0.83 & 0.83 & 0.83 & 0.83 \\
\hline$x_{4}$ & 0.67 & 0.68 & & 0.57 & 0.69 & \\
\hline$x_{5}$ & 0.69 & & & 0.66 & & \\
\hline
\end{tabular}

\subsection{Factor analysis of items}

Principal factor analysis was used to investigate the factor structure of the combined SIRI, Selfregulation, Agitation and Inhibition Scales, using the polychoric correlation matrix of the 70 items included in the survey. Separate analyses were conducted for male and female subjects, due to the response distribution differences discussed previously. In each case, the correlation matrix eigenvalues indicated that either a four-factor or five-factor solution could be appropriate. Factor rotation using the varimax criterion was then applied to obtain uncorrelated factors approximating simple structure (Harman, 1976). Only those items with loadings greater than or equal to 0.3 and no significant cross-loadings were retained. Increasing the number of factors in the solution above five did not result in additional meaningful factors. However, decreasing the number of factors in the solution to three yielded another possible solution for investigation. Further reduction led to significant cross-loading and loss of conceptual meaning.

Cronbach's coefficient alpha is commonly used as a measure of how well items in a given factor measure their common attribute (McDonald, 1985). Table 4 summarises the coefficient alpha values obtained for each of the potential solutions for both the female and male subgroups. For both groups, the five-factor and four-factor solutions involve at least one factor with poor reliability, whereas good overall reliability is exhibited by the three-factor solution. In addition, Tucker's coefficient of congruence (Harman, 1976) was used to assess the agreement between factors when subjects were divided into two groups. Since the subjects were all twins, pairs of twins were separated and categorised according to their order of registration with the Australian Twin Registry. Similar results were obtained for this split-half analysis for male and female subjects. The three-factor solution demonstrated extremely high congruence for all factors ( 0.95 or greater), whereas the other two potential solutions had at least one factor with significantly lower congruence. On the basis of these two tests, the five-factor and four-factor solutions are rejected in favor of the three-factor solution.

The separate three-factor solutions for male and female subjects derived from the varimax rotation appear in Table 5, with the two solutions displaying strong similarity. In each case, Factor 1 consists entirely of Agitation subscale items from the Differentiation scale. Factor 2 consists mainly of SIRI Type 4(a) and Self-regulation items, while Factor 3 includes all five items from the 
Table 5

Factor loadings for SIRI, Self-regulation, Agitation and Inhibition scales

\begin{tabular}{|c|c|c|c|c|c|c|c|}
\hline \multirow[b]{2}{*}{ Scale } & \multirow[b]{2}{*}{ Item } & \multicolumn{2}{|l|}{ Factor 1} & \multicolumn{2}{|l|}{ Factor 2} & \multicolumn{2}{|l|}{ Factor 3} \\
\hline & & $\begin{array}{l}\text { Females } \\
(n=1985)\end{array}$ & $\begin{array}{l}\text { Males } \\
(n=859)\end{array}$ & $\begin{array}{l}\text { Females } \\
(n=1985)\end{array}$ & $\begin{array}{l}\text { Males } \\
(n=859)\end{array}$ & $\begin{array}{l}\text { Females } \\
(n=1985)\end{array}$ & $\begin{array}{l}\text { Males } \\
(n=859)\end{array}$ \\
\hline \multirow[t]{5}{*}{ SIRI (Type 1) } & 1 & & & & & 0.58 & 0.65 \\
\hline & 8 & & & & & 0.56 & 0.63 \\
\hline & 15 & & & & & 0.53 & 0.50 \\
\hline & 22 & & & & & 0.60 & 0.63 \\
\hline & 36 & & & & & 0.54 & 0.59 \\
\hline \multirow[t]{4}{*}{ SIRI (Type 4a) } & 25 & & & 0.55 & 0.54 & & \\
\hline & 39 & & & 0.45 & 0.48 & & \\
\hline & 46 & & & 0.49 & 0.55 & & \\
\hline & 67 & & & 0.58 & 0.67 & & \\
\hline SIRI (Type 4b) & 35 & & & & & $-0.36^{\mathrm{c}}$ & -0.49 \\
\hline \multirow[t]{9}{*}{ SIRI (Type 5) } & 5 & & & & & 0.57 & 0.45 \\
\hline & 12 & & & & & 0.60 & $0.49^{\mathrm{c}}$ \\
\hline & 26 & & & & & 0.41 & $0.30^{\mathrm{c}}$ \\
\hline & 33 & & & & & 0.32 & 0.37 \\
\hline & 68 & & & & & 0.35 & 0.13 \\
\hline & 19 & & & $0.34^{c}$ & 0.40 & & \\
\hline & 40 & & & 0.45 & $0.38^{\mathrm{c}}$ & & \\
\hline & 47 & & & $0.41^{\mathrm{c}}$ & 0.47 & & \\
\hline & 61 & & & 0.40 & $0.42^{c}$ & & \\
\hline \multirow[t]{17}{*}{ Self-regulation } & 1 & & & 0.41 & 0.40 & & \\
\hline & 2 & & & 0.35 & 0.49 & & \\
\hline & 3 & & & 0.41 & 0.42 & & \\
\hline & 4 & & & 0.28 & 0.39 & & \\
\hline & 5 & & & 0.35 & 0.39 & & \\
\hline & 7 & & & 0.44 & 0.45 & & \\
\hline & 9 & & & 0.59 & 0.58 & & \\
\hline & 10 & & & 0.52 & 0.48 & & \\
\hline & 12 & & & 0.63 & 0.68 & & \\
\hline & 13 & & & 0.29 & 0.33 & & \\
\hline & 14 & & & 0.33 & 0.37 & & \\
\hline & 15 & & & $0.44^{\mathfrak{c}}$ & 0.45 & & \\
\hline & 16 & & & $0.47^{c}$ & 0.54 & & \\
\hline & 17 & & & 0.52 & 0.56 & & \\
\hline & 19 & & & 0.45 & 0.48 & & \\
\hline & 20 & & & 0.55 & 0.55 & & \\
\hline & 21 & & & 0.43 & 0.46 & & \\
\hline \multirow[t]{6}{*}{ Agitation } & 3 & 0.62 & $0.68^{c}$ & & & & \\
\hline & 4 & 0.75 & $0.74^{\mathrm{c}}$ & & & & \\
\hline & 4 & 0.75 & $0.74^{c}$ & & & & \\
\hline & 6 & 0.73 & 0.76 & & & & \\
\hline & 7 & 0.60 & 0.65 & & & & \\
\hline & 9 & 0.68 & 0.62 & & & & \\
\hline
\end{tabular}


Table 5-continued

\begin{tabular}{|c|c|c|c|c|c|c|c|}
\hline \multirow[b]{2}{*}{ Scale } & \multirow[b]{2}{*}{ Item } & \multicolumn{2}{|l|}{ Factor 1} & \multicolumn{2}{|l|}{ Factor 2} & \multicolumn{2}{|l|}{ Factor 3} \\
\hline & & $\begin{array}{l}\text { Females } \\
(n=1985)\end{array}$ & $\begin{array}{l}\text { Males } \\
(n=859)\end{array}$ & $\begin{array}{l}\text { Females } \\
(n=1985)\end{array}$ & $\begin{array}{l}\text { Males } \\
(n=859)\end{array}$ & $\begin{array}{l}\text { Females } \\
(n=1985)\end{array}$ & $\begin{array}{l}\text { Males } \\
(n-859)\end{array}$ \\
\hline Agitation & $\begin{array}{l}12 \\
17\end{array}$ & $\begin{array}{l}0.60 \\
0.70\end{array}$ & $\begin{array}{l}0.73 \\
0.71\end{array}$ & & & & \\
\hline Inhibition & $\begin{array}{r}5 \\
11 \\
13\end{array}$ & & & & & $\begin{array}{l}0.53 \\
0.61 \\
0.52\end{array}$ & $\begin{array}{l}0.63 \\
0.57 \\
0.63\end{array}$ \\
\hline SIRI (Type 2) & $\begin{array}{r}2 \\
30 \\
37 \\
58 \\
65\end{array}$ & $\begin{array}{l}0.48 \\
0.45 \\
0.47 \\
0.52 \\
0.35\end{array}$ & $\begin{array}{l}0.41 \\
0.45 \\
0.44 \\
0.48 \\
0.39\end{array}$ & & & $\begin{array}{l}0.39 \\
0.41 \\
0.34 \\
0.33 \\
0.46\end{array}$ & $\begin{array}{l}0.54 \\
0.41 \\
0.41 \\
0.46 \\
0.56\end{array}$ \\
\hline
\end{tabular}

'Indicates that the item is significantly cross-loaded with another factor for the relevant subgroup.

SIRI Type 1 (cancer-prone) classification that were included in the survey, as well as the majority of the rationality/anti-emotionality SIRI Type 5 .

The items from the SIRI Type 2 scale are not in any of the factors derived from the factor analysis, as only items with no significant cross-loadings have been retained. As demonstrated in the last five rows of Table 5, all Type 2 items were significantly cross-loaded between Factor 1 (Agitation items) and Factor 3 (SIRI Types 1 and 5).

Table 6 contains the results of a Tucker's factor congruence test carried out to compare the factors derived for the female subjects vs those for the male subjects. No significant differences were found between the three factors, as demonstrated by the extremely high congruence coefficients.

Table 6

Tucker's coefficient of factor congruence (females vs males)

\begin{tabular}{lrrr}
\hline \multicolumn{4}{c}{ Males $(n=859)$} \\
\cline { 2 - 4 } & \multicolumn{1}{c}{1} & \multicolumn{1}{c}{3} \\
\hline Females $(n=1985)$ & & \\
1 & 0.97 & -0.42 & 0.52 \\
2 & -0.43 & 0.98 & -0.20 \\
3 & 0.36 & -0.07 & 0.97 \\
\hline
\end{tabular}


Table 7

Cronbach $\alpha$ for SIRI, Self-regulation and Differentiation scales, and for varimax-rotated principal factors from item analysis

\begin{tabular}{llll}
\hline & \multicolumn{2}{l}{ Cronbach $\alpha$} & \\
\cline { 2 - 4 } Scale & $\begin{array}{l}\text { Females } \\
(n=1985)\end{array}$ & $\begin{array}{l}\text { Males } \\
(n=859)\end{array}$ & $\begin{array}{l}\text { Revised scales } \\
\text { (Roberts et al., 1995) }\end{array}$ \\
\hline Type 1 (cancer prone) & 0.82 & 0.80 & 0.85 \\
Type 2 (CHD prone) & 0.81 & 0.82 & 0.84 \\
Type 4 (combined healthy) & 0.73 & 0.75 & - \\
Type 4a (healthy +) & 0.66 & 0.63 & 0.77 \\
Type 4b (healthy -) & 0.74 & 0.76 & - \\
Type 5 (rational/antiemotional) & 0.72 & 0.72 & 0.70 \\
Self-regulation & 0.83 & 0.84 & - \\
Agitation & 0.89 & 0.90 & - \\
Inhibition & 0.75 & 0.75 & - \\
Factor 1 (agitation) & 0.87 & 0.83 & \\
Factor 2 (healthy +/self-regulation) & 0.86 & 0.88 & \\
Factor 3 (cancer-prone, rational/antiemotional) & 0.83 & 0.83 & \\
\hline
\end{tabular}

\subsection{Factor analysis of scales}

Principal factor analysis was also performed on the scale scores of the variables listed in Table 2 , again with separate analyses being conducted for males and females. Factor rotation was used to obtain factors approximating simple structure, with the promax criterion being used in order to permit oblique solutions. In this case, eigenvalues indicated two-factor and three-factor solutions could be regarded as acceptable, with extremely similar factor structures being derived for males and females. In the three-factor solution, the first factor consisted of SIRI Types 2 and 4(b) and the Agitation scale, the second was comprised of SIRI Types 1 and 5 plus the Inhibition scale, and the third factor consisted of SIRI Type 4(a) and the Self-regulation scale. Interfactor correlations for males and females were 0.27 and 0.28 between Factors 1 and 2; 0.26 and 0.19 between Factors 2 and $3 ;-0.36$ and -0.42 for Factors 1 and 3 .

The two-factor solution divided the scales into one factor consisting of SIRI Types 1, 2 and 4(b) and the Agitation scale, and another comprised of SIRI Types 4(a), 5 and the Self-regulation and Inhibition scales. For males the correlation between these factors was -0.14 for males and only -0.05 for females. Varimax factor rotation, which enforces an orthogonality constraint on the derived factors, produced solutions with similar overall structure to those outlined above for both the two-factor and three-factor solutions.

\subsection{Reliability comparison}

The upper half of Table 7 summarises the Cronbach alpha coefficient values obtained from the polychoric matrix of item responses for each of the Short Interpersonal Reactions Inventory types 
included in the Over 50's Twin Study, as well as the Self-regulation, Agitation and Inhibition scales. Results for females and males are listed separately. Also listed are the results for the corresponding revised scales as defined by Roberts ct al. (1995). As in (Table 1), Type 4 is considered both as a whole, and in its constituent positive-scored and reverse-scored components. The Cronbach coefficient values for the three factors obtained by principal factor analysis (Table 4) are repeated in the lower half of Table 7 for convenience. These demonstrate the factors obtained to be generally at least as reliable as the corresponding original scales, although a small decrease from the original scale was observed for the cancer-prone factor, which now also represents rationality/antiemotionality. Of particular interest is the considerable improvement in reliability of Factor 2 (healthy +/self-regulation) over its constituent scales, and the corresponding Revised Scale of Roberts et al. (1995).

\section{Discussion}

Despite the significant differences observed between male and female subjects for the response distributions of several of the SIRI Type scales, no such differences were observed for the interscale correlations. The factor structures derived separately for male and female subjects also demonstrated high congruency. Hence, although item responses and score distributions differ for male and female subjects, the relationships between the SIRI Types and the Self-regulation and Differentiation scales are common to both groups.

In this study, as in others (Larsson et al., 1995; Roberts et al., 1995; Amelang et al., 1996), SIRI Types 1 and 2 were found to be significantly correlated. Significant correlations also existed between Type 2 and the Agitation subscale, and Type 1 and both the Agitation and Inhibition subscales. In an analysis of factor structure, Type 2 as defined by Grossarth-Maticek was found to be significantly cross-loaded between one factor consisting of the Agitation scale and another based on SIRI Type 1. These correlations are different from those previously observed (Pfundt, 1994), where Type 1 was correlated with Inhibition but not Agitation, whereas Type 2 was found to lightly correlate with the Inhibition scale, in addition to the significant correlation with the Agitation scale. Although trends in intercorrelation values with scale scores were in the expected direction, neither the Agitation nor the Inhibition scales demonstrated significant ability to discriminate between Type 1 and Type 2 subjects.

The high degree of correlation between Type 4 and the Self-regulation scale, and the negative correlation of Type 4 with Agitation, are in agreement with the results of Pfundt (1994), who did not separate the two halves of the Type 4 scale in his analysis. However, the extremely low correlation observed between Types 4(a) and 4(b), along with the lack of consistency in the pattern of correlations with other scales, reinforces the findings of Roberts et al. (1995) and Larsson et al. (1995) that the two different measures of the "healthy" Type 4 are in fact measuring two separate constructs.

Type 5 was not found to be strongly correlated with any other scale, although significant correlation with Inhibition was observed. Factor analysis suggests that the majority of Type 5 items are closely related to Type 1 , and it is interesting to note that these Types are those proposed by Grossarth-Maticek as cancer-prone.

In the future we hope to test the validity of the scales against disease data obtained from the 
Over 50's Twin Study. We also anticipate making use of the twin structure of this data to estimate the importance of genetic and environmental variation in individual differences in these scales.

\section{Acknowledgements}

This paper is dedicated to the memory of Hans Eysenck, who encouraged us to pursue research into the area of personality and disease proneness, and who assisted us with translation of the Selfregulation and Differentiation scales. We also thank Mr George Landers and Dr Bernd Kalinna for help with translation. This work was partly supported by a donation from Mr George Landers. We thank Fran Boyle and Len Roberts for their work in constructing the questionnaire, David Duffy and Kim-Anh Do for advice regarding analysis, Olivia Zheng for administering the mailout, John Pearson for data management and Nirmala Pandeya for data cleaning. Most of all, we thank the twins for their cooperation.

\section{Appendix: Reduced form of the Short Interpersonal Reactions Inventory, and English Versions of the Self-regulation and Differentiation Scales}

\begin{tabular}{|c|c|c|c|c|c|}
\hline & & \multicolumn{2}{|c|}{ Males $(n=859)$} & \multicolumn{2}{|c|}{ Females $(n=1985)$} \\
\hline \multicolumn{2}{|c|}{ SIRI No. } & $\% Y$ & $\% \mathrm{~N}$ & $\% \mathrm{Y}$ & $\% \mathrm{~N}$ \\
\hline \multicolumn{6}{|c|}{ Type 1 items } \\
\hline 1 & I find it very difficult to stand up for myself & 9 & 83 & 22 & 65 \\
\hline 8 & I prefer to agree with others rather than assert my own views & 22 & 68 & 30 & 56 \\
\hline 15 & $\begin{array}{l}\text { I try to do what people close to me want rather than look after } \\
\text { my own needs }\end{array}$ & 44 & 39 & 59 & 28 \\
\hline 22 & $\begin{array}{l}\text { I tend to give in and abandon my own aims to achieve harmony } \\
\text { with other people }\end{array}$ & 37 & 46 & 57 & 30 \\
\hline 36 & $\begin{array}{l}\text { I tend to accept, without protest, conditions which work against } \\
\text { my own interests }\end{array}$ & 20 & 67 & 25 & 59 \\
\hline \multicolumn{6}{|c|}{ Type 2 items } \\
\hline 2 & $\begin{array}{l}\text { I have been complaining for years about aspects of my life but am } \\
\text { unable to change them }\end{array}$ & 14 & 80 & 17 & 75 \\
\hline 30 & $\begin{array}{l}\text { I always seem to be confronted with the undesirable aspects of } \\
\text { people and conditions }\end{array}$ & 7 & 80 & 10 & 78 \\
\hline 37 & Certain people keep interfering with my personal development & 6 & 87 & 12 & 81 \\
\hline 58 & $\begin{array}{l}\text { I cannot control excitement or stress in my life because this } \\
\text { depends on conditions over which I have no control }\end{array}$ & 17 & 73 & 26 & 60 \\
\hline 65 & $\begin{array}{l}\text { I can express my aims and desires clearly but feel it is impossible } \\
\text { to achieve them }\end{array}$ & 17 & 65 & 26 & 51 \\
\hline \multicolumn{6}{|c|}{ Type $4 a$ items } \\
\hline 25 & When I fail to achieve objects I can easily change tack & 65 & 17 & 56 & 20 \\
\hline 39 & I can usually change my behavior to suit conditions & 77 & 11 & 76 & 11 \\
\hline 46 & $\begin{array}{l}\text { I am usually capable of finding new points of view and successful, } \\
\text { sometimes surprising, solutions for problems }\end{array}$ & 72 & 8 & 69 & 10 \\
\hline
\end{tabular}




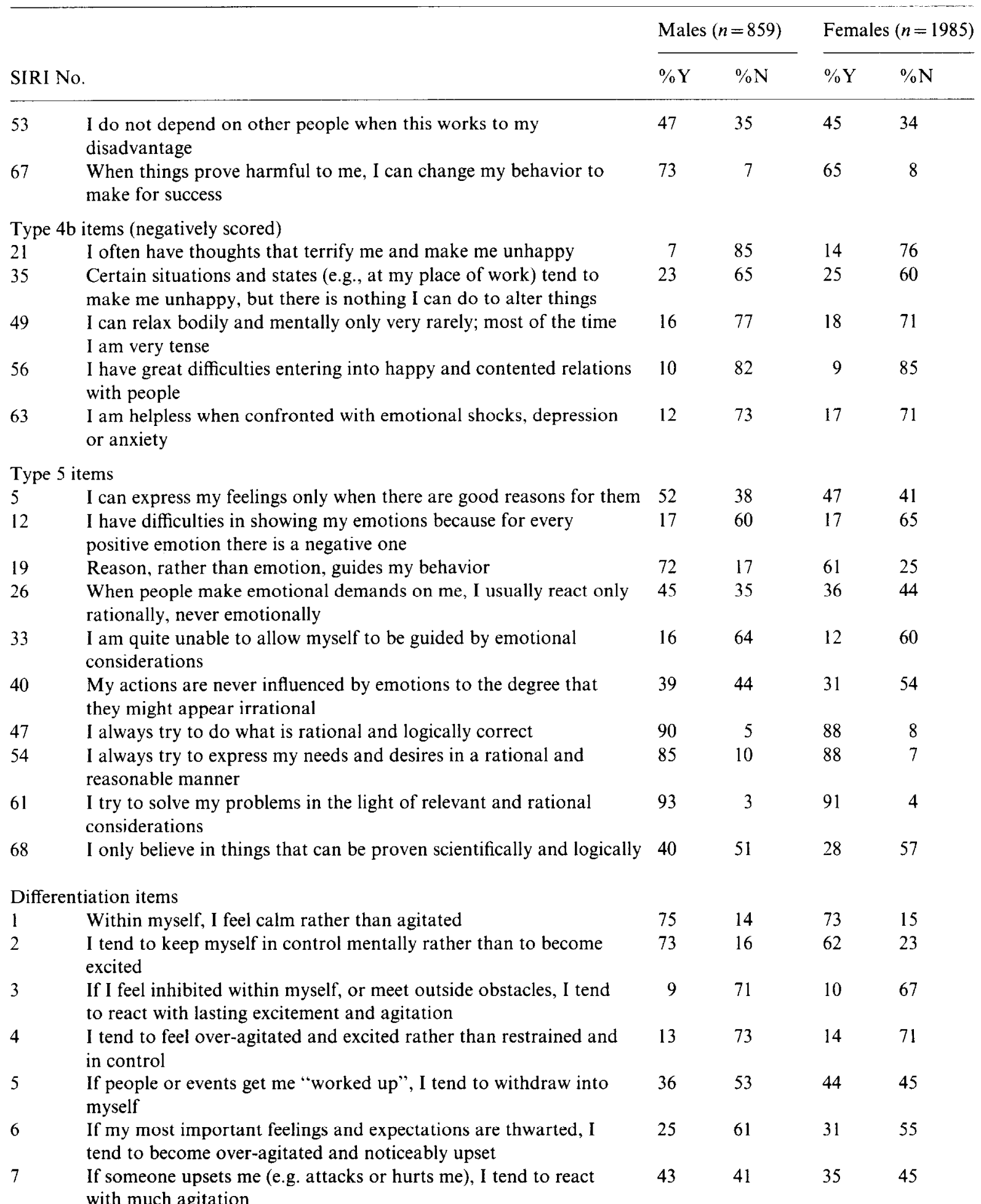




\begin{tabular}{|c|c|c|c|c|c|}
\hline & & \multicolumn{2}{|c|}{ Males $(n=859)$} & \multicolumn{2}{|c|}{ Females $(n=1985)$} \\
\hline \multicolumn{2}{|c|}{ SIRI No. } & $\% Y$ & $\% \mathrm{~N}$ & $\% \mathrm{Y}$ & $\% \mathrm{~N}$ \\
\hline 8 & $\begin{array}{l}\text { If someone offends me, I tend to control myself and show a calm } \\
\text { exterior }\end{array}$ & 67 & 22 & 70 & 18 \\
\hline 9 & $\begin{array}{l}\text { If someone rejects me, I tend to become excited within myself and } \\
\text { show that I'm upset }\end{array}$ & 15 & 72 & 20 & 67 \\
\hline 10 & $\begin{array}{l}\text { If I'm having trouble solving a problem, I tend to stop myself from } \\
\text { getting worked up and show a calm exterior }\end{array}$ & 64 & 21 & 66 & 17 \\
\hline 11 & $\begin{array}{l}\text { If people or events excite me, I usually hold back so that it hardly } \\
\text { shows }\end{array}$ & 30 & 53 & 24 & 64 \\
\hline 12 & $\begin{array}{l}\text { If people or events hinder me, I tend to react with lasting agitation } \\
\text { and excitement }\end{array}$ & 16 & 67 & 16 & 66 \\
\hline 13 & $\begin{array}{l}\text { If people get me upset, I hold back from expressing my feelings to } \\
\text { them for a long time }\end{array}$ & 44 & 42 & 52 & 37 \\
\hline 14 & $\begin{array}{l}\text { When I stop myself from doing something, I tend to become } \\
\text { noticeably worked up }\end{array}$ & 12 & 72 & 14 & 69 \\
\hline 15 & $\begin{array}{l}\text { If an event gets me worked up, I tend to stop myself from doing } \\
\text { what I'd really like to do }\end{array}$ & 33 & 47 & 34 & 45 \\
\hline 16 & $\begin{array}{l}\text { I see myself as someone who tends to remain controlled rather } \\
\text { than become agitated }\end{array}$ & 74 & 15 & 74 & 14 \\
\hline 17 & $\begin{array}{l}\text { I see myself as someone who tends to get agitaicu rather than stay } \\
\text { in complete control }\end{array}$ & 20 & 67 & 19 & 68 \\
\hline \multicolumn{6}{|c|}{ Self-regulation items } \\
\hline 1 & I always have a rest when I need it & 51 & 41 & 49 & 43 \\
\hline 2 & $\begin{array}{l}\text { I arrange my bed so that I feel well in it (e.g. mattress is not too } \\
\text { hard or too soft) }\end{array}$ & 81 & 13 & 89 & 7 \\
\hline 3 & $\begin{array}{l}\text { In the evenings, I go to bed at a time that is right - not too late; } \\
\text { not too early. }\end{array}$ & 74 & 18 & 75 & 19 \\
\hline 4 & $\begin{array}{l}\text { I feel I'm eating what is right for me in terms of both quantity and } \\
\text { quality }\end{array}$ & 80 & 11 & 78 & 13 \\
\hline 5 & $\begin{array}{l}\text { The type and amount of daily exercise I take contributes to my } \\
\text { feeling of well-being. }\end{array}$ & 71 & 16 & 71 & 17 \\
\hline 6 & I am emotionally satisfied with my attitude towards religion. & 83 & 8 & 83 & 6 \\
\hline 7 & $\begin{array}{l}\text { If particular people do me no good, I am able to distance myself } \\
\text { from them. }\end{array}$ & 78 & 12 & 75 & 14 \\
\hline 8 & $\begin{array}{l}\text { If particular situations do me no good, I am able to distance myself } \\
\text { from them. }\end{array}$ & 67 & 18 & 66 & 17 \\
\hline 9 & $\begin{array}{l}\text { If particular ways of acting or behaving do me no good, I'm able } \\
\text { to change them. }\end{array}$ & 74 & 9 & 73 & 8 \\
\hline 10 & $\begin{array}{l}\text { If my actions or opinions don't lead to a desired outcome, I am } \\
\text { able to change them. }\end{array}$ & 72 & 11 & 61 & 15 \\
\hline 11 & I am not afraid of a lack of success or even complete failure. & 50 & 34 & 53 & 28 \\
\hline 12 & $\begin{array}{l}\text { I can easily distance myself from conditions or situations that } \\
\text { harm me in the long run. }\end{array}$ & 77 & 8 & 75 & 7 \\
\hline 13 & $\begin{array}{l}\text { If certain people keep harming me, I avoid expecting positive } \\
\text { things from them. }\end{array}$ & 78 & 10 & 82 & 7 \\
\hline 14 & $\begin{array}{l}\text { I'm not inhibited from doing things to bring conditions and } \\
\text { situations that are good for me. }\end{array}$ & 61 & 17 & 51 & 21 \\
\hline
\end{tabular}




\begin{tabular}{|c|c|c|c|c|c|}
\hline \multirow{2}{*}{\multicolumn{2}{|c|}{ SIRI No. }} & \multicolumn{2}{|c|}{ Males $(n=859)$} & \multicolumn{2}{|c|}{ Females $(n=1985)$} \\
\hline & & \multirow{2}{*}{$\frac{\% \mathrm{Y}}{81}$} & \multirow{2}{*}{$\frac{\% \mathrm{~N}}{14}$} & \multirow{2}{*}{$\frac{\% Y}{77}$} & \multirow{2}{*}{$\frac{\% \mathrm{~N}}{15}$} \\
\hline 15 & I am able to relax on a regular basis. & & & & \\
\hline 16 & I can always overcome negative mental states (e.g. fear or depression). & 74 & 13 & 69 & 16 \\
\hline 17 & I do my work in such a way that it is good for me. & 84 & 7 & 85 & 6 \\
\hline 18 & $\begin{array}{l}\text { Through my actions, I achieve success in my occupation which gives } \\
\text { me satisfaction. }\end{array}$ & 92 & 3 & 87 & 4 \\
\hline 19 & $\begin{array}{l}\text { Through my actions, I secure the money I need for my lifestyle and } \\
\text { aspirations. }\end{array}$ & 78 & 12 & 64 & 21 \\
\hline 20 & $\begin{array}{l}\text { Through my actions, I achieve satisfying relationships with people } \\
\text { who matter to me. }\end{array}$ & 87 & 4 & 89 & 3 \\
\hline 21 & $\begin{array}{l}\text { I avoid situations that make excessive demands so I rarely suffer from } \\
\text { over-tiredness. }\end{array}$ & 40 & 46 & 38 & 50 \\
\hline 22 & I only smoke when it gives me a feeling of comfort. & 11 & 81 & 10 & 82 \\
\hline 23 & I only drink alcohol when it does me good. & 35 & 56 & 30 & 61 \\
\hline
\end{tabular}

Differentiation item scoring: inhibition scale-items $1,2,5,8,10,11,13,15,16$. Agitation scale-items 3, 4, 6, 7, 9, 12, $14,17 . \% \mathrm{Y} / \% \mathrm{~N}$-percentage who agree/disagree with statement, based on responses from 859 males and 1985 females. The percentage who gave "Don't Know" as a response is given by the remainder $(100-\% \mathrm{Y}-\% \mathrm{~N})$.

\section{References}

Amelang, M., \& Schmidt-Rathjens, C. (1992). Personality, stress and disease: some results on the psychometric properties of the Grossarth-Maticek and Eysenck inventories. Psychological Reports, 71, 1251-1263.

Amelang, M., Schmidt-Rathjens, C., \& Matthews, G. (1996). Personality, cancer and coronary heart disease: Further evidence on a controversial issue. British Journal of Health Psychology, I, 191-205.

DeGroot, M.H. (1986). Probability and statistics. Reading, MA: Addison Wesley.

Eysenck, H.J. (1991). Smoking, personality and stress: psychosocial factors in the prevention of cancer and coronary heart disease. New York: Springer-Verlag.

Friedman, M. \& Rosenman, R.H. (1974). Type A behavior and your heart. New York: Knopf.

Greer, S., \& Watson, M. (1985). Towards a psychobiological model of cancer: psychological considerations. Social Science and Medicine, 20, 773-777.

Grossarth-Maticck, R., \& Eysenck, H. J. (1990). Personality, stress and discase: deseription and validation of a new inventory. Psychological Reports, 66, 355-373.

Harman, H.H. (1976). Modern factor analysis. Chicago: University of Chicago Press.

Larsson, G., Nordström, L., Ljunggren, G., Nyberg, A.-B., Resare, B., Schedwin, G., \& Wahlgren, M. (1995). The Grossarth-Maticek and Eysenck Personality Types, health-related behavior, and indicators of transitory ill-health. European Journal of Personality, 9, 75-87.

McDonald, R.P. (1985). Factor analysis and related methods. New Jersey: Lawrence Erlbaum Associates.

Pfundt, C. (1994). Die Bedeutung von Hemmung und Aufregung für die Differenzierung von Typ1 und 2 der Grossarth'schen Typologie. Deutsche Zeitschrift für Onkologie, 26, 67-75.

Roberts, L. J., Duffy, D. L., \& Martin, N. G. (1995). A psychometric evaluation of the Short Interpersonal Reactions Inventory (SIRI) in an Australian twin sample. Personality and Individual Differences, 18, 307-320.

Temoshok, L. (1987). Personality, coping style, emotion and cancer: towards an integrative model. Cancer Surveys, 6 , 545-567.

SAS Institute (1995). SAS Version 6.11 [computer program]. Cary, NC: SAS Institute. 